\title{
Passive Sociopathy
}

\begin{abstract}
Naum Ilievski
Prof. Dr. Faculty of Psychology, International Slavic University “Gavrilo R. Derzhavin”, Sveti Nikole, R. North Macedonia
\end{abstract}

Angelina Ilievska

MD, Psychotherapist, Psychiatrist, Private Practice, Skopje, R. North Macedonia

\begin{abstract}
In the domain of complex relational phenomena and social behaviors, passive sociopathy (N. Ilievski) is described as a form of inadequate behavior with a negative impact not only in the immediate, but also in the wider social context as a global psycho-social phenomenon. This dysfunctional pattern is an indicator of psychosocial distortion with unproductive to extremely passive and risky behavior. Analysis and description of this phenomenon through the three psychological components: emotional, cognitive, and behavioral, in correlation with exogenous factors and influences, from the aspect of Christian psychotherapy and the model of Transactional analysis. The practice of Christian psychotherapy sets prayer as a central point of the FCP method in cultivating empathy as a dimension of emotional intelligence through which an emotionally healthy base is built in the person with adequate prosocial behaviors. Contemporary man, faced with the challenges of modern trends - in which the mass media of hyper information plays an important role - is flooded with negative information that changes the threshold of his perception and sensitivity to the level of discount, emotional dullness, to extreme insensitivity as the main characteristic of passive sociopathy.
\end{abstract}

Keywords: passive sociopathy, Christian psychotherapy, transactional analysis, prayer, prosocial behavior

\section{Introduction}

Passive sociopathy, as a phenomenon, is intriguing in contemporary psychology, but it also has serious implications in the domain of sociology.

The authors of this study have developed this concept, which is considered to be an epiphenomenon of modern individualism and narcissism, structured in the egocentric lifestyle that results in utter insensitivity. In other words, it is a metaphorically pathological existence, which is outside the category of mental disorders, and is different from that defined by the authors as "active sociopathy," where the individual experiences an early formed and pervasive form of dissociative behavior with destructive consequences on their ecosystem, and wide-ranging social damage. 
With this newly created term the authors bridge the gap between descriptive psychology and modern sociology. Thus, a new transcendental phenomenology is tackled, described from the aspect of Christian psychotherapy and the personality theory concepts of Transactional analysis.

The aim of this paper is to describe passive sociopathy as a new psycho-social phenomenon and, without exaggeration, as an anomaly and distortion of the modern living of contemporary man. The authors point out that they do not aim at psychiatrization or critical pathologization of this phnomenon as a clinical entity, but they would like to underline its existential dimension and sociological effects. However, aiming at a better understanding of its meaning, the description of the term sociopathy cannot be avoided, above all, through the prism of the medical model.

\section{Psychological Perspective}

In the classical psychiatric classification, sociopathy is a diagnostic entity that belongs to the category of Dissocial personality disorder (DPD) (ICD 10, 1992) and its equivalent Antisocial personality disorder according to the Diagnostic and Statistical Manual of Mental Disorders (DSM) (APA, 2013). In the past the term 'psychopathy' was applied.

In applied psychology often a distinction is made between these two - sociopathy and psychopathy. "Psychopathy and sociopathy are different cultural labels applied to the diagnosis of antisocial personality disorder" (Psych Central, 2015). Namely, 'psychopathic' referred to early-emerging disorders assumed to have an underlying constitutional or genetic basis. Subsequently, the term 'sociopathy', conveying the idea of antisocial behavior as largely social in origin, was advanced by Birnbaum (1909) as a challenge to the idea that such disorders were fundamentally genetic (Skeem et al., 2011, pp. 95-162).

The historic definitions with a starting psychological conceptualization date back to 1800 described as manie sans délire - insanity without delusion (Pinel, 1806), and later in the works of Pritchard (1835; 'moral insanity') and for the first time the term 'psychopathic' was introduced in 1891 by the German psychiatrist J. L. Koch.

The psychological description of this entity was later elaborated in the work of several psychiatrists, among whom the following are singled out (Kraepelin, 1904, 1915; Schneider, 1950/1958): "charm, self-assurance, social dominance, attention seeking, persuasiveness, and shallow affectivity," as well as (Pinel, 1806/1962; Schneider, 1950/1958): "brutality, emotional coldness, and callous exploitation of others."

\section{Sociological Dimension}

According to contemporary views, sociopathy is much more frequent than it may be supposed and is not limited to the small percentage of detected and clinically diagnosed personality disorders. Unfortunately, it is more often evident in the everyday lives of people whose behavior is more and more socially deviant. "It is not only our personal morality that is at stake, but also the ethical meaning of our society, our culture, our entire civilization" (Gottlieb, 2019).

Some authors find that this phenomenon is on a global scale and is deeply rooted in the structure of society. "The idea of a 'sociopathic society' is necessary to understand today's world," noted the author Charles Derber in his book "Sociopathic Society" (2016, p. 11). The 
socio-political vocabulary does not recognize such terminology, because the idea is closely connected to a specific category of people with mental illness, that is, personality disorder.

Namely, "medical professionals believed that any person or even a group of people could be shown to have the same tendencies as a sociopath; although these tend to be for limited periods in conjunction with a specific aim. In these cases people are aware of the emotional damage to other people which can be caused but choose to ignore it for what they see as the greater good" (Franklin, 2016).

\section{Classification of Mental Disorders according to Christian Psychotherapy}

Christian psychotherapy, based on Orthodox patristics, classifies human existence into two categories: counternatural and natural way of life.

In the counternatural way of life there are three mental health conditions that modern psychology and Christian psychotherapy grade and denote as religious neurosis, religious personality disorder (psychopathy and sociopathy) and religious psychosis (demonic possession).

Religious neurosis occurs to those that cannot control their thoughts and feelings. Religious personality disorder occurs to those that cannot control their words and deeds - they are also characterized by enormous insensitivity. The third gradation is religious psychosis with a completely lost self-control and it has almost nothing to do with a classical mental illness such individuals may be even extraordinarily intelligent and functional within the social setting.

The three conditions can be and often are subtle. They arise as a result of one's striving "towards a permanent satisfaction of their needs on account of reality, which results in narcissistic fixations, which are further a subject and basis of psychopathology. From the point of view of Orthodox anthropology and psychotherapy, this corresponds with the counternatural way of life, which occurs at three downward levels of mental illness: contamination of one's heart due to the satisfaction of his passions, darkening of the mind (cognitive distortions), and identification with the archetype of evil, because of the permanent willful choosing of sin as a deviation from the natural way of life" (Илиевски \& Илиевска, 2018, pp. 209-212).

"The natural way of life of a Christian comprises three spiritual conditions - healing, archetypal, perfect by likeness - are leveled by the Holy Fathers in Christian psychotherapy as: cleansing of the heart from the passions, illumination of the mind - with the gift of the mind-and-heart prayer, and deification" (Наум, 2020).

This is the model of life that is offered to people and that makes possible, through a personal relation, the actualization of the individual into person.

\section{Passive Sociopathy - Notions and Bases}

"There are two kinds of people who have been destined to be powerful in the world: psychopaths, who feel nothing, or emphats, who are deeply in touch with the feelings of others." - Claude Steiner

Insensitivity is the main characteristic of those people with distortions of the Divine image within them. Such persons are widely known as psychopaths and sociopaths. There is also a greater danger from active personality disorder, and that is passive sociopathy. 
Modern people are simply bombed, through the electronic media, about many and most different misfortunes, very often with lethal consequences, and they simply have neither the time nor the knowledge to process all the information into them and to avoid greater negative consequences. Insensitivity is one of the negative consequences, which in modern people is recognized as passive sociopathy.

What, in short, is passive sociopathy? It is when one does no evil to anyone, but is at the same time insensitive towards the people suffering in his immediate and wider environment; and helps no one. Passive sociopathy is the widest spread disease of modern times. Everyone, more or less, is suffering from this disease. The bad habit is the main problem in passive sociopathy, as well as in many other cases of insensitivity, like - conformism, hedonism, egocentric model of life.

\section{Methodological Framevork applied to the Concept}

In this analytical-descriptive study, an integrative approach is applied with the methodology of Transactional analysis as a theory of personality and social theory and the practice of Christian psychotherapy.

The phenomenon of passive sociopathy is analyzed through three dimensions: cognitive, emotional and behavioral.

For a more precise explanation of the dynamics of the process Schiff's concepts are applied: frame of reference, passivity, passive behavior, discount and discount matrix.

In the domain of Christian psychotherapy, the FCP Method (Acceptance, Thanksgiving, Selfdiscernment, Quiesence, Prayer) is presented, in which prayer has an essential role.

\section{Mechanisms, Dynamics, Developmental Phases of Passive Sociopathy}

The main characteristics of passive sociopathy are: thinking errors in the cognitive sphere, insensitivity in regard to the emotional dimension, and non-acting as a behavior component. Thus, the passive sociopath redefines the ideas about himself, others, and reality. It results in internal cognitive distortions (over-detailing, generalization, escalation, fantasizing), emotional distortions (emotional bluntness, insensitivity), and external - reality distortions.

"An internal frame of reference is one in which the person attends to internal stimuli and fantasies and does not attend to external situation. Perceptions are often distorted by an emphasis on personal feelings. An external frame of reference is one in which the person overemphasize aspects of other people or the reality situation and discounts aspects of him or herself" (Schiff \& Schiff, 1975, pp. 290-294).

At the beginning the individual is within the domain of the external reference frame, where the source of induction is in the field of mass media with excessive presenting of information, which overwhelms the consumers by their quantity and quality (most often unpleasant and negative). Under such circumstances the consumer, who on account of the aggressive external stimuli has a constant externalizing energetic cathexa, starts discounting his inner world. In the field of technology man becomes a technical being prone to hyper-intellectualization, with gradual but certain neglecting of the natural capacities of intuition and empathy. Moreover, the continual exposure to negative stimuli (information) alters the stimulus threshold to a level of hyper tolerance so that there are also alterations on the level of consciousness, 
cognitive functions, and emotions. Such person becomes nonconscious, with a lack of understanding and reasoning, emotionally blunt to a level of insensitivity.

The next level is when the individual is excessively absorbed in the internal reference frame and ignores the external reality. This occurs as a result of the emphasized process of egocentric individualization and emphasized narcissism. Hence, the internalizing mechanisms with an energetic cathexa of the self and the personal content are activated.

In both cases there are the mechanism of discounting and grandiosity of the external and the internal aspect, whose function is the sustaining of the reference frame.

"Discounting is functional manifestation of either a contamination or an exclusion" (Schiff \& Schiff, 1971, pp. 71-78).

This is the way to sustain passivity - inaction, which as a psychological phenomenon lies at the basis of passive sociopathy. "Passivity means inaction. Passivity is displayed when one does nothing or does something inappropriately, or ineffectively. (...) Passivity in feeling, thinking, or doing disrupts the balance of social functioning and results in internal distress or behavior disorders" (Karve, 2018).

Passivity is a form of pathology characterized by manifesting personal incapacity for acting, which results in serious consequences and fatal outcomes. Passive behaviors are forms of passivity and dysfunctional forms of behavior.

Jacqui and Aaron Schiff, the founders of the Cathexis schools, a branch of Transactional analysis, have identified four types of passive behavior (Schiff \& Schiff, 1971, pp. 71-78):

1. Doing nothing.

2. Over-adaptation.

3. Agitation.

4. Incapacitation and violence.

Regarding the above-described, passive sociopathy may be classified as a form of the first two passive behaviors - doing nothing and over-adaptation.

In the first form of "doing nothing" the person does not act and does not take part in active behaviors in solving the problem. This matches the behavior of passive sociopaths, who have an ignoring and insensitive attitude towards the sufferings and misfortunes of others.

The second form of "over-adaptation" is linked to the conformism as a condition of a personal and safe comfort zone, where the person takes adaptive position with passivity regardless of the alarming situation and the unfavorable circumstances. Thus, dysfunctionally adapting, one is sustaining the dynamics of his personal comfort.

"Discounting is the mechanism in which passivity operates. Discounting is unawarely minimizing, maximizing or ignoring an aspect of reality, a capacity, an endowment which is relevant to ending a situation or solving a problem safely" (Karve, 2018).

Regarding the application of the discount matrix (Mellor \& Schiff, 1975) the authors classify passive sociopathy at the highest level on the first stage, ignoring the existence of a stimulus, problem, or option. "The person who discounts believes or acts as thou some aspects of the self, other people, or reality is less significant than it actually is" (Mellor \& Schiff, 1975, pp. 295-302). 
Viewed prognostically, discounting at the first level results in unfavorable outcome in situations, which can lead to fatal consequences.

\section{Discount Matrix}

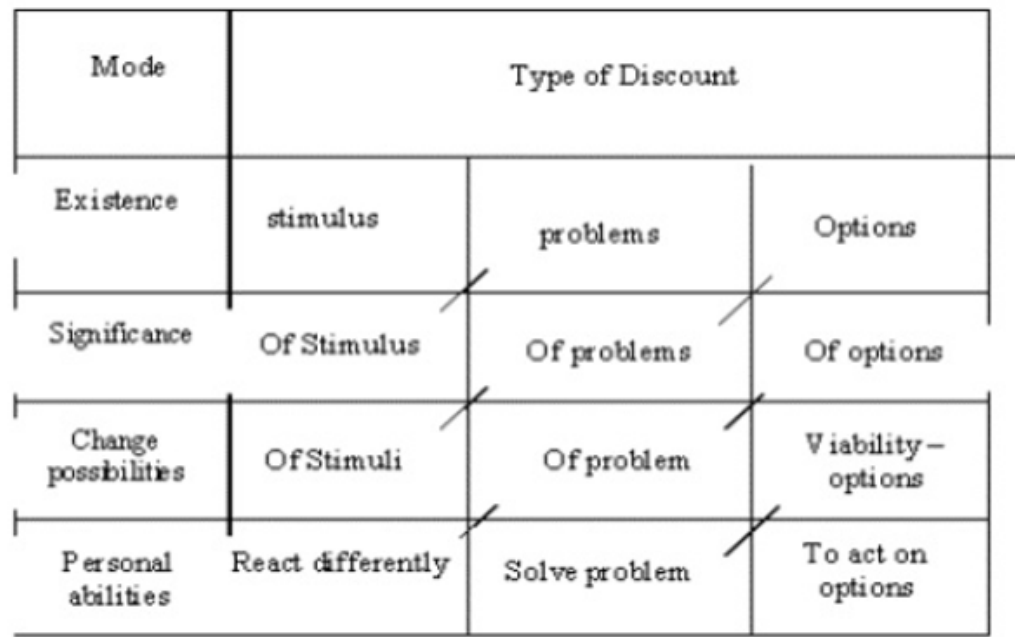

\section{Results - The Prayer in Cultivation of Empathy and Building of Emotional Intelligence}

"Only the first uttered prayer may be called by the name of prayer, the remaining prayerful invocation of the Godman Christ is love." - Metropolitan of Strumica Nahum

The Jesus prayer is the central point of the FCP Method (Ilievski \& Ilievska, 2017, pp. 93-98) and the basic practice of the ascetic-hesychastic struggle. It is the instrument through which one is healed going through the three stages of spiritual development: cleansing of the heart from the passions, illumination of the mind, and God-likening, or Christian perfection (Ilievski \& Ilievska, 2019, pp. 15-22).

By struggling in prayer, beside emotional, we also create spiritual consciousness, which is an existential position with a profound awareness about what we are in relation to God. Whenever one starts praying being aware that Christ is his repentance and everything else, then the seriousness and the repentance arise from this awareness; when one prays for the entire world, especially for those that are specifically suffering, then the seriousness, repentance and concentration, beside from Christ, arise, somehow naturally, from his humanity - which is the best combination.

By this manner of prayer one harmonizes the Divine and his worldview; he builds his personal and catholical consciousness.

Prayer is closely connected to the phenomenon of opening of one's heart. "The occurrence when grace for the first time manifests itself in such a way in the heart is called opening of the heart, whereas the place where God's grace is manifested is called place of the heart. One and the same grace, energy of God, enacts such occurrence: both the opening of one's heart and the keeping of the place of the heart active" (Наум, 2011, pp. 118-119). 
This phenomenon, described also within the frames of psychology, occurs as a result of the application of certain psychological techniques and methods. Namely, the renowned Transactional analyst Claude Steiner, the creator of the concept of emotional literacy or intelligence with a heart, describes some effects that he names opening of the heart. These were recognized as a result of the work done by the work group Stroke City formed in the distant 1969. By applying the techniques of the Stroke economy (Steiner, 1971, pp. 9-15) (exercises for giving and receiving positive strokes), beside the expected enlargement of emotional consciousness and learning of the ways of communicating through contacts, it was found that the technique affected, above all, upon the capacity for loving as a powerful way to open the hearts of the participants.

In his work "Emotional Literacy," Steiner writes about this unexpected epiphenomenon: "They spoke of loving feelings, of having an open heart, of a transcendence experience of affection, an 'oceanic' feeling" (Steiner, 2003, p. 22). By this was discovered the profound connection between the strokes and the feeling of love.

\section{Discusion- Between Mysticism and Empiricism}

Prayerful practice cultivates person's empathy and builds his emotional intelligence. Prayer enlarges sensibility, sympathy, emotional consciousness and a new spiritual consciousness is built with a universal and transcendental dimension of love. It is the experience and a phenomenon of the human soul that enables the existence outside the borders of what is subjective, limited, insufficient and egoistic.

Even the new academic trends are equipped with empirical data from the practice of prayer and other spiritual practices. Namely, neurotheology studies the effects from various religious and spiritual practices (meditation, prayer, rituals and myths development) and spiritual experiences and maps neurochemical alterations as a consequence of their effects.

The research in this area has lead to the conclusion that, "intense, long-term contemplation of God and other spiritual values appears to permanently change the structure of the brain that control our moods, give rise to our conscious notion of self, and shape our sensory perception of the world. Contemplative practices strengthen specific neurological circuits that generate peacefulness, social awareness, and compassion for others" (Newberg \& Waldman, 2010).

\section{Conclusion and Recommendations}

"If you want God to hear your prayer, pray for the whole world and let the whole world pray through you." - Metropolitan of Strumica Nahum

The only cure for this modern pandemic - passive sociopathy, is the prayer for the entire world. We live in times characterized by global catastrophes and suffering, and it is absolutely necessary that we practice prayer for the entire world, which should be our only idea whenever we start praying. Only then will our prayer have seriousness and repentance. Only such a prayer can be heard by God.

"For the prayer to be perfect, as much as possible, it must not be uttered only for ourselves, but it needs to encompass the entire world - each man; from the present, the past and from the future" (Наум, 2020).

Furthermore, concrete help matters as well. If one does not strive to offer concrete help, he remains an ordinary, religious, passive sociopath. 
Conformism, hedonism, narcissism, and accentuated individualism are bad habits in the creation of the social script of passivity. The formative characters of the global culture, the modern trends and the mass media influence are not always beneficial for the individual. In such circumstances the individual develops an adaptive position, altered energetic cathexa between its external and its internal reference frame and distorted index of reality by creating a basis for sociopathic tendencies. On the other hand, the hope and striving for formation of healthy personalities and creating a humane and empathetic society should be the collective work of each individual. Bad habits are eliminated by good practices.

\section{References:}

[1] American Psychiatric Association. (2013). Diagnostic and Statistical Manual of Mental Disorders (DSM-5®), (5th Ed.). Washington, DC: American Psychiatric Association.

[2] Derber, C. (2016). Sociopathic Society: A People's Sociology of the United States. New York, NY: Routledge.

[3] Franklin, C. (2016). Sociopath: The - Sociopath - Laid Bare. Scotts Valley, CA: CreateSpace.

[4] Gottlieb, R. (2019). Morality and the Environmental Crisis. Cambridge, UK: Cambridge University Press.

[5] ICD 10: International Statistical Classification of Diseases and Related Health Problems Volume 1, (10th Ed.). (1992). Washington, DC: American Psychiatric Publishing, Inc.

[6] Karve, A. (2018). Transactional Analysis Theory - Passivity, Discounting, Passive Behaviours, Symbiosis. Retrieved from https://tatheoryandpracticebyajitkarve.blogspot.com/2018/04/transactional-analysistheory-passivity.html

[7] Ilievski, N., Ilievska, A. (2017, Sep.-Dec.). Sociological Dimensions of the FCP Method according to Christian Psychotherapy in Coping with Stress and Suffering. European Journal of Social Sciences, Education and Research, 11(1), pp. 93-98.

[8] Ilievski, N., Ilievska, A. (2019). Introduction to the Core Concepts of Christian Psychotherapy. European Center for Science Education and Research, European Journal of Multidisciplinary Studies, 4(1), pp. 15-22.

[9] Илиевски, Н., Илиевска, А. (2018, April). Психолошка глад, консумеризам и масинтројекција - два модела на живот, Меѓународен дијалог: Исток - Запад (психологија и образование), 5(3), pp. 209-212.

[10] Mellor, K., Schiff, E. (1975). Discounting. Transactional Analysis Journal, 5(3), pp. 295302, DOI: $10.1177 / 036215377500500321$

[11] Наум, М. С. (2011). Школа за исихазам: основна. Велјуса, Македонија: Манастир Воведение на Пресвета Богородица Елеуса, pp. 118-119.

[12] Наум, М. С. (2020). Прирачна психоанализа. Retrieved from http://mpc.org.mk/MPC/SE/vest.asp?id=7275

[13] Наум, М. С. (2020). Молитва за цел свет. Retrieved from http://mpc.org.mk/MPC/SE/vest.asp?id=7321 
[14] Newberg, A., Waldman, M. R. (2010). How God Changes Your Brain: Breakthrough Findings from a Leading Neuroscientist. New York, NY: Ballantine Books.

[15] Pinel, P. (1962). A Treatise on Insanity. New York, NY: Hafner Publishing Company.

[16] Psych Central (2015). Differences Between a Psychopath vs Sociopath. Retrieved from https://psychcentral.com/blog/differences-between-a-psychopath-vs-sociopath/

[17] Schiff, J. L., Schiff, A., Schiff, E. (1975, July). Frames of Reference. Transactional Analysis Journal, 5(3), pp. 290-294.

[18] Schiff A. W., Schiff J. L. (1971). Passivity. Transactional Analysis Journal, 1(1), pp. 71-78, DOI: $10.1177 / 036215377100100114$

[19] Skeem, J. L., Polaschek, D. L., Patrick, C. J. \& Lilienfeld, S. O. (2011, Dec). Psychopathic Personality: Bridging the Gap Between Scientific Evidence and Public Policy. Psychological Science in the Public Interest, 12(3), pp. 95-162. DOI: 10.1177/1529100611426706

[20] Steiner, C. (1971). The Stroke Economy. Transactional Analysis Journal, 1(3), pp. 9-15, DOI: $10.1177 / 036215377100100305$

[21] Steiner, C. (2003). Emotional Literacy; Intelligence with a Heart. Fawnskin, CA: Personhood Press. 